\title{
Integrated information and prediction Web Service WaterPUCK General concept
}

Lidia Dzierzbicka-Glowacka ${ }^{1, *}$, Maciej Janecki ${ }^{1}$, Beata Szymczycha ${ }^{2}$, Dawid Dybowski ${ }^{1}$, Artur Nowicki ${ }^{1}$, Żaneta Kłostowska ${ }^{2}$, Hanna Obarska-Pempkowiak ${ }^{3}$, Piotr Zima ${ }^{3}$, Beata Jaworska-Szulc ${ }^{3}$, Jaromir Jakacki ${ }^{1}$, Adam Szymkiewicz ${ }^{3}$, Stefan Pietrzak ${ }^{4}$, Grażyna Pazikowska-Sapota ${ }^{5}$,Ewa Wojciechowska $^{3}$, Grażyna Dembska ${ }^{5}$, Marcin Wichorowski ${ }^{6}$, Michat Białoskórski ${ }^{7}$ and Tadeusz Puszkarczuk ${ }^{8}$

${ }^{1}$ Institute of Oceanology PAS, Physical Oceanography Department, Powstańców Warszawy 55, 81-712 Sopot, Poland

${ }^{2}$ Institute of Oceanology PAS, Marine Chemistry and Biochemistry Department, Powstańców Warszawy 55, 81-712 Sopot, Poland

${ }^{3}$ Gdańsk University of Technology, Faculty of Civil and Environmental Engineering, G. Narutowicza 11/12, 80-233 Gdańsk, Poland

${ }^{4}$ Institute of Technology and Life Sciences, Department of Water Quality, al. Hrabska 3, Falenty, 05-090 Raszyn, Poland

${ }^{5}$ Maritime Institute in Gdansk, Department of Environment Protection, Długi Targ 41/42, 80-830 Gdańsk, Poland

${ }^{6}$ Institute of Oceanology PAS, IT Department, Powstańców Warszawy 55, 81-712 Sopot, Poland

${ }^{7}$ Academic Computer Centre in Gdansk, G. Narutowicza 11/12, 80-233 Gdańsk, Poland

${ }^{8}$ Municipality of Puck, 10 Lutego 29, 84 - 100 Puck, Poland

\begin{abstract}
In this paper, general concept of a new method as 'Integrated information and prediction Web Service WaterPUCK' for investigation influence of agricultural holdings and land-use structures on coastal waters of the southern Baltic Sea is presented. WaterPUCK Service is focused on determination of the current and future environmental status of the surface water and groundwater located in the Puck District (Poland) and its impact on the Bay of Puck (the southern Baltic Sea) environment. It will highly desired tool for land-use and environment management. WaterPUCK combines several different components and methods such as retrospective analyses of existing monitoring data sets, in situ measures and the application of various models to estimate main mechanisms and threats responsible for the pollution transport from the agricultural holdings and land-use structure to the surface and groundwater and potential predictability of environment change of the Puck District and the Bay of Puck ecosystem. WaterPUCK Service will integrate several models, such as a surface water model based on SWAT, a groundwater flow model based on MODFLOW, a 3D-ecohydrodynamic model of the Bay of Puck called EcoPuckBay and an agriculture calculator called CalcGosPuck. The WaterPUCK Service is constructed as part of the project with the same name 'WaterPUCK'.
\end{abstract}

\section{Introduction}

Water pollution is one of the biggest threats and challenging problems of the World. Hence providing innovative solutions for proper environment management is essential for both sustainable, thrifty and rational usage of drinking water and protection of water resources. Therefore, water management in agriculture ecosystems should bring together experts in fields ranging across the social sciences, ecology, agricultural sciences, soil and water science while development studies should explore the essential relationships and linkages between land use and water management within them.

The Puck District together with the Bay of Puck (Fig. 1) is an example of region that sustainable growth and management is a challenging task due to its complex structure. Puck District is one of the largest municipalities in Pomeranian Voivodeship situated in the northern part of Poland, at the southern coast of the Baltic Sea.

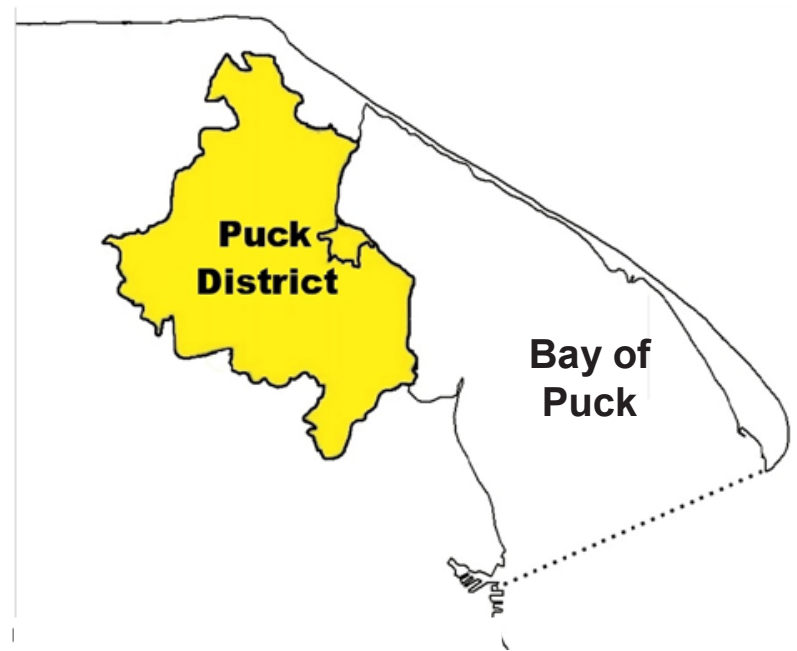

Fig. 1. Map of the Puck District and the Buy of Puck.

District has numerous watercourses and rivers. Puck District is agriculture area with dynamically growing tourism (mainly due to water sports and beautiful

\footnotetext{
Corresponding author: dzierzb@iopan.gda.pl
} 
beaches) and agro-tourism sector. The main source of Puck District inhabitants incomes come from agriculture, fishery and tourism.

Bay of Puck is an inner basin of the Bay of Gdansk, one of the few embayments at the southern coast of Baltic Sea. It is microtidal area, salinity ranges from 3 to 7 PSU and is typical for the large region of southern Baltic. The bay contains all types of habitats (from muddy to stony bottom) and variety of shore types (sandy beaches, gravel beds, stony outcrops, clay cliffs, vegetated river mouths etc). Therefore, it is protected as a Natura 2000 site under both the birds and habitats directives; it is also a designated Baltic Sea Protected Area (BSAP), and its inner waters are part of the Coastal Landscape Park. Bay of Puck has also been subjected to strong anthropogenic pressure (pollution and nutrification). It receives most human derived nutrient loads from rivers, groundwater discharge, atmospheric deposition, and point sources while the coastal ecosystem controls the biogeochemical transformations of P-, N- compounds (phosphate, nitrate, DON, etc.) through the close coupling between water and sediments. For an optimal economic growth combined with integrated management and for the implementation and application of strategic program of scientific research and development work concepts on the ecosystem including land use and coastal ecosystem it is necessary to study in a holistic approach the link between the catchment (including groundwater) and the coastal ecosystem mainly Puck District and how climate change will affect the river water constituents and the biogeochemistry of the coastal waters and sediments. The aim of this paper is to present the general concept of the integrated information and prediction Web Service WaterPUCK to intensively agricultural used catchment and its use for catchment management.

\section{MATERIAL AND METHODS}

Solutions to water access, land degradation, nutrient management and ecosystem services have to be developed in consideration of what influences the environment and communities across landscapes, not just what works influences the farm. Therefore, the main result of the project will be Integrated information and prediction Service "WaterPUCK" developed by both improving the best available models and combining them with new models.

WaterPUCK will be developed basing on SWAT (Soil and Water Assessment Tool) [1-5], groundwater flow model (based on Modflow) [6], 3D ecohydrodynamic model of the Bay of Puck EcoPuckBay (based on the POP code) [7-8] and integrated agriculture calculator called "CalcGosPuck" [9].

SWAT model (Soil and Water Assessment Tool) has a river basin structure and will be use to predict the influence of changes in the way of farming for: water balance, erosion degree, nitrogen and phosphorus compounds pollution, pesticides, bacteria and heavy metals. SWAT is a model of river basin, which only contains the component of retention and groundwater recharge modelling in a simplified way.

SWAT model is a physically based, time continuous simulation model that operates on a daily time step at catchment scale [1-2]. It is designed to evaluate management practices on water quality and sediment production in large watersheds with varying of soils and land use over long periods of time. The watershed is divided into a number of subbasins where the smallest unit of discretisation HRU (Hydrological Response Units) is the result of overlay of the same of soil type, land use and slope. The modelling processes such as: surface runoff, soil water content, nutrient cycle, crop growth and management practices are simulated for each HRU and then aggregated for the subbasin by weighted average. SWAT simulates complete cycle of nitrogen and phosphorus taking into account nutrient mineralization, decomposition and immobilization [3]. The SWAT model requires a large amount of input data. Their quality has a most significant effect on the quality of the results. A diagram showing the required data and way of processing is shown in Figure 2.

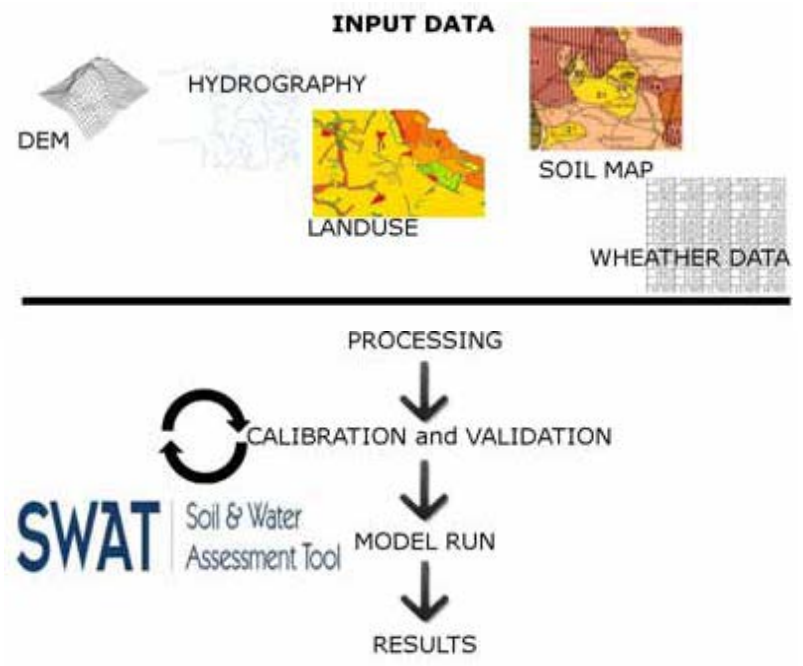

Fig. 2. SWAT model schema; source: own elaboration [10]

Based on the knowledge of the hydrogeological system, a steady-state mathematical model of the Puck multi-aquifer system is developed. The extent of the multi-aquifer system is limited by the rivers watersheds and the drainage area of the Puck Bay. The mathematical modelling is based on the finite difference solution of the MODFLOW program [11], which is the most commonly used code for simulating groundwater flow. For complex regional multi-aquifer models, usually steady state, three-dimensional finite difference solution is used [12]. Such a three-dimensional model is also constructed in this case. The three-dimensional conceptual regional model of this hydrogeological system is shown in Figure 3 .

Developed within the framework of this project, the model of the Puck Bay "EcoPuckBay" (Fig. 4) will be a three-dimensional ecohydrodynamical model of higher vertical and horizontal resolution that assimilates satellite data. 


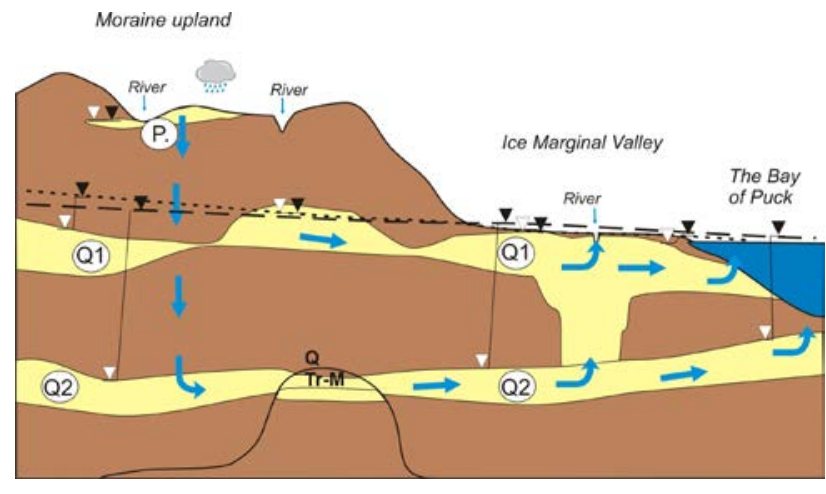

Fig. 3. Simplified diagram of groundwater flow, Q1 and Q2 upper and lower Quaternary aquifers, P - local perched groundwater.

EcoPuckBay model consists of active ocean, ecosystem and ice modules, coupled together with active land module (SWAT plus ModFlow) which provide data, such as freshwater inflow and nutrient discharge from rivers and ground, and passive atmospheric module which provide data such as weather forecasts from external sources (UM ICM). From the side of the open sea, boundary conditions will be fed from the threedimensional model of the ecosystem for the Baltic Sea 3D CEMBS (www.cembs.pl).

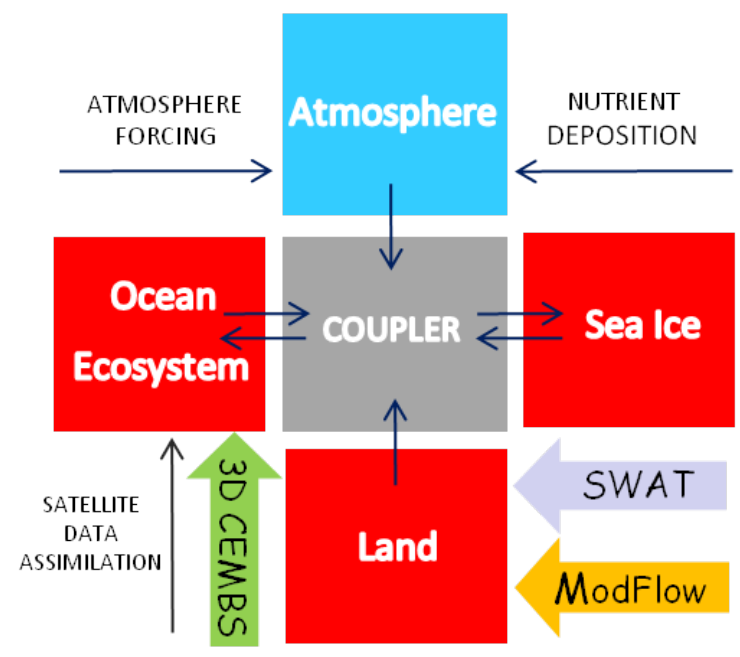

Fig. 4. Configuration of the 3D EcoPuckBay model

The model horizontal resolution is $1 / 960^{\circ}$, which corresponds to ca. $115 \mathrm{~m}$ grid. Vertically model is divided into 19 layers. The first of 5 layers is 0.4 meters thick. 3D EcoPuckBay model will generate 72-hour forecast which include currents, temperature, salinity and ice parameters. In addition, the model will forecast ecological parameters i.e. nutrients, pesticides, dissolved oxygen concentration and biomass of phytoplankton and zooplankton in the entire water column. Each of these variables will be calculated with a second-order advection-diffusion, partial differential equation:

$$
\frac{\partial C}{\partial t}+\left(V+w_{s}\right) \nabla C=\frac{\partial}{\partial z}\left(D_{z} \frac{\partial C}{\partial z}\right)+\sum_{i=1}^{2} \frac{\partial}{\partial x_{i}}\left(D_{x_{i}} \frac{\partial C}{\partial x_{i}}\right)+Q_{C}
$$

where $C$ is each model variable, $\mathrm{V}(u, v, w)$ is the velocity vector, $w_{\mathrm{s}}$ is the sinking velocity of pelagic detritus, $D_{z}$ and $D_{x}$ are vertical and horizontal turbulent diffusion coefficients and $Q_{C}$ is the biogeochemical source-sink term. EcoPuckBay model will also determine the spatiotemporal changes in the quality of marine waters in respect to specific pollution indicators.

The CalcGosPuck calculator will be working as an independent application by which will can be to plan the fertiliser usage by farmers in order to obtain the best harvest policy. Preparation of the nutrient balance at farm level by the "at farm gate" method involves determination of input and output streams on the farm (Fig. 5).

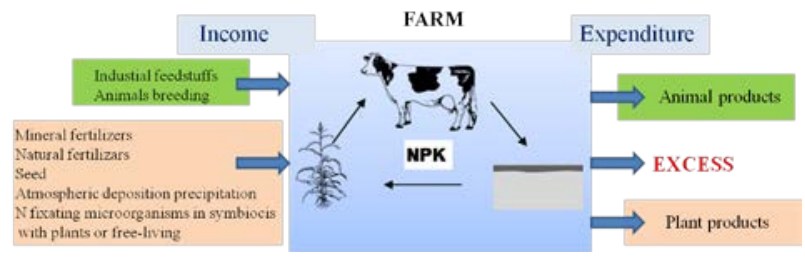

Fig. 5. Components of the "at farm gate" nutrient balance method (CalcGosPuck) [9]

Inputs are the masses of nutrients brought onto the farm in the form of:

1) Purchased materials:

- mineral fertilisers

- commercial feedstuffs

- breeding and replacement animals

- other agricultural inputs, for example, manure, straw, seed

2) Biological fixation by plant material (legumes and nitrogen)

3) Atmospheric deposition

4) Biological fixation in soil by non-symbiotic microorganisms (nitrogen).

Outputs are the masses of nutrients leaving the farm in the form of:

1) Products sold:

- plant products (e.g. cereals, potatoes, sugar beet, oilseed, fruits, vegetables etc.)

- animal products (live animal, milk, eggs, wool, etc.);

2) Random events, such as fallen animals, accidental crop destruction (e.g. by fire or flooding) [9].

The difference between inputs and outputs is defined as the balance (surplus or deficit).

\section{Result}

WaterPUCK will merge all models and result in an integrated innovative tool that enables simulations and the creation of scenarios and projects the effects of changes in land use on the loads of chemicals being transported through surface and groundwaters to the Bay of Puck (Fig. 6).

Examples of preliminary results presenting the work of individual modules of the WaterPUCK Service are presented in the table 1 and Figures (7-10). 


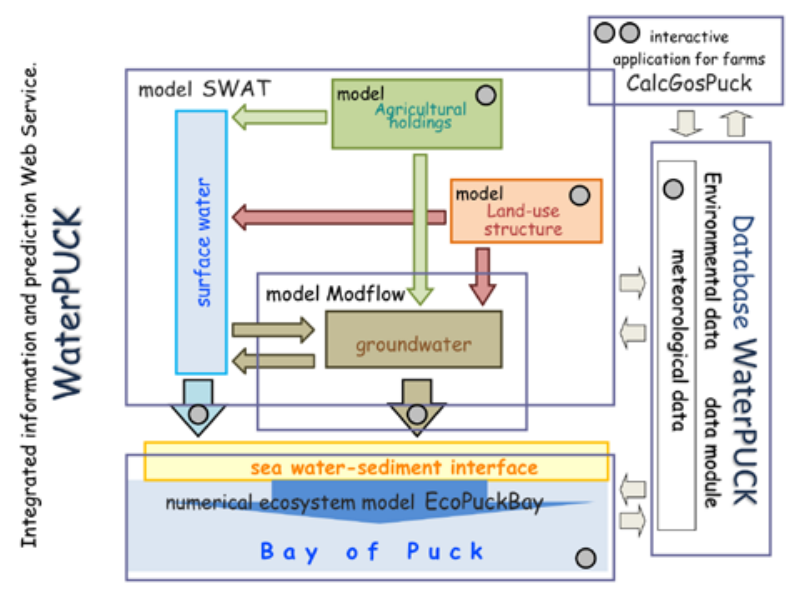

Fig. 6. The shame of water and contaminant fluxes covered in WaterPUCK.

The input GIS data for the SWAT model has been prepared. The basis is 10 meter resolution Digital Elevation Model (DEM). Files in a regular grid with an interval of $1 \mathrm{~m}$, have been obtained from the Head Office of Geodesy and Cartography in Poland. To cover the area of Puck District 254 LAS sheets have been used, creating merged numeric terrain model. This data has been used for automatic catchment delineation and its division into 23 sub-catchments (Fig. 7a) (areas from 5 to $38 \mathrm{~km}^{2}$ ), of which 3 discharge rainwater directly to the Puck Bay. Next, drain lines analysis in SWAT has been performed (Fig. 7b) and the main watercourses were marked out: Plutnica canal $(8.5 \mathrm{~km})$, Bladzikowski stream $(8 \mathrm{~km})$, Mrzezino canal $(11 \mathrm{~km})$ and the estuary section of the Reda River $(8 \mathrm{~km})$.

A land development map (Fig. 7c) on the basis of soil and agricultural maps in the scale of 1:25000 has been created. Soil maps (Fig. 7d) were used in a scale of 1:5000 obtained in shp format (ESRI Shapefile) from Voivodeship Centre of Geodesy and Cartography Documentation in Gdańsk (WODGiK). Soil cover has been categorized due to their agricultural usefulness fertility (including black, podzolic and brown soils) and infiltration capacity - granulometric composition (including dusts, sands, gravels, clays, etc.). The Hydrologic Response Units (HRUs) will be created based on this data. Due to the functionality of the model, the optimal number of HRU (level of the model detail) will be analyzed.

Table 1 shows the obtained values of the highest peak discharge with the probability of exceeding $1 \%$ for main watercourses.

Table 1. Highest peak discharge with the probability of exceeding $1 \%\left(\mathrm{Q}_{\max 1 \%}\right)$ for the main watercourses in the Puck District.

\begin{tabular}{|l|c|}
\hline \multicolumn{1}{|c|}{ Object } & $\mathbf{Q}_{\max \%}\left[\mathrm{~m}^{3} / \mathbf{s}\right]$ \\
\hline Plutnica & $\mathbf{1 4 . 7 4}$ \\
\hline Bladzikowski & $\mathbf{3 . 5 3}$ \\
\hline Gizdepka & $\mathbf{6 . 4 9}$ \\
\hline Reda River & $\mathbf{4 1 . 3 3}$ \\
\hline
\end{tabular}

The three-dimensional regional ModFlow model consists of two Quaternary aquifers (Q1 and Q2, Fig. 3).

These fluvioglacial aquifers, built of sands and gravels, are separate by till deposits. Both aquifers are hydraulically connected and confined, except areas where till cover was eroded. These aquifer system is drained mainly by the Bay of Puck, however river valleys and ice marginal valleys also play a significant role (Fig. 3 and Fig. 8). a)
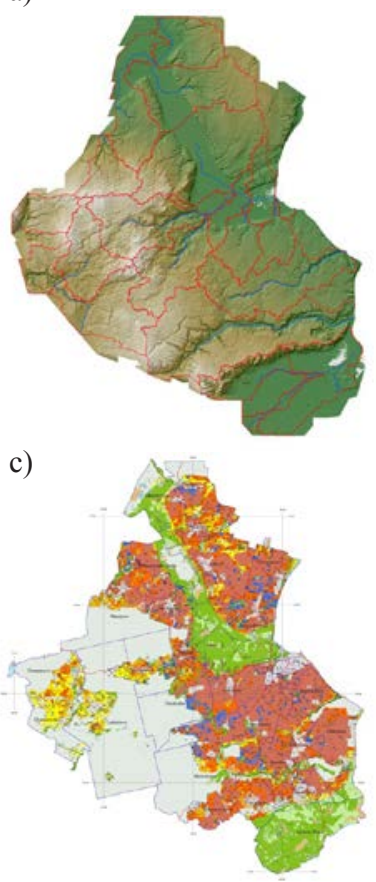
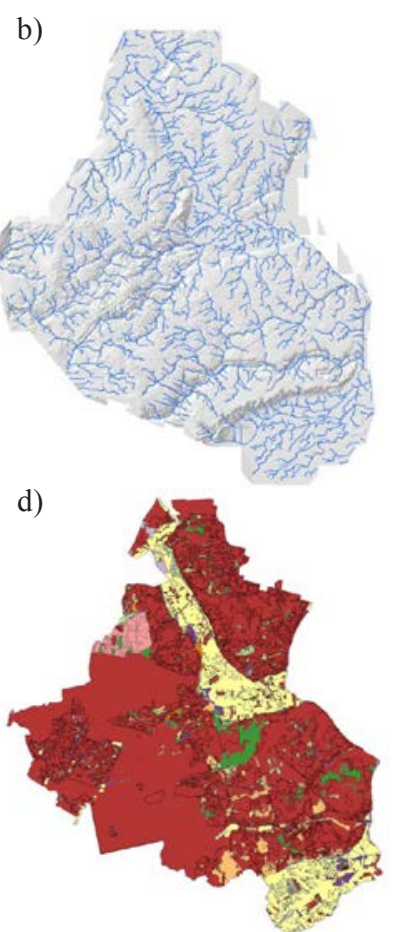

Fig. 7. Input GIS data layers used to build the SWAT Model: a) DEM of watershed with watercourses, b) drain lines, c) land use and cover map, d) soil cover map.

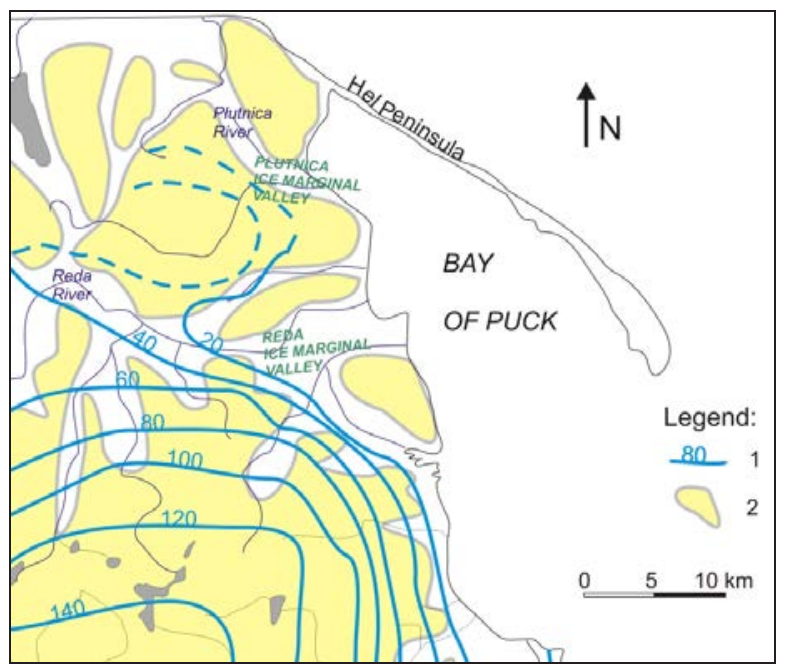

Fig. 8. Hydraulic head distribution for the Quaternary (Q1) aquifer (m a.s.l.). 1 - head contour line, 2 - moraine upland [6]

Locally, at depths up to $5 \mathrm{~m}$ below surface, groundwater occurs in type of perched aquifer or in the form of sand lenses enclosed in till deposits (Fig. 3). These local perched aquifers are not in hydraulic contact 
with the main Quaternary aquifer. Perched aquifers lie much higher and recharge lower aquifers. An example of preliminary results of hydraulic head distribution for the main Quaternary aquifer is shown in Figure 8.

Figures 9 and 10 show the modelled results from the 3D EcoPuckBay model. For example, distributions of the temperature (Fig. 9) and salinity (Fig. 10) in the upper layer sea in Bay of Puck in November are presented.

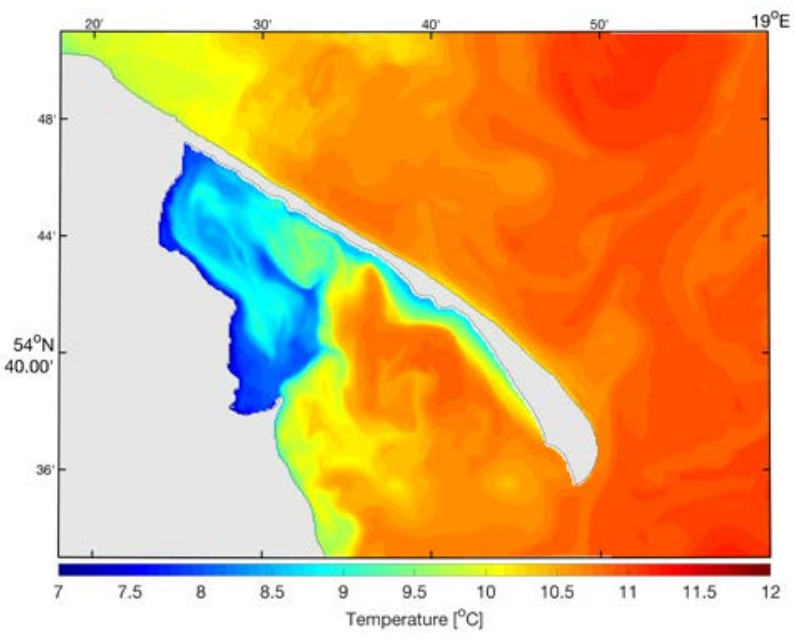

Fig. 9. Distribution of the sea surface temperature in Bay of Puck in November (3D EcoPuckBay).

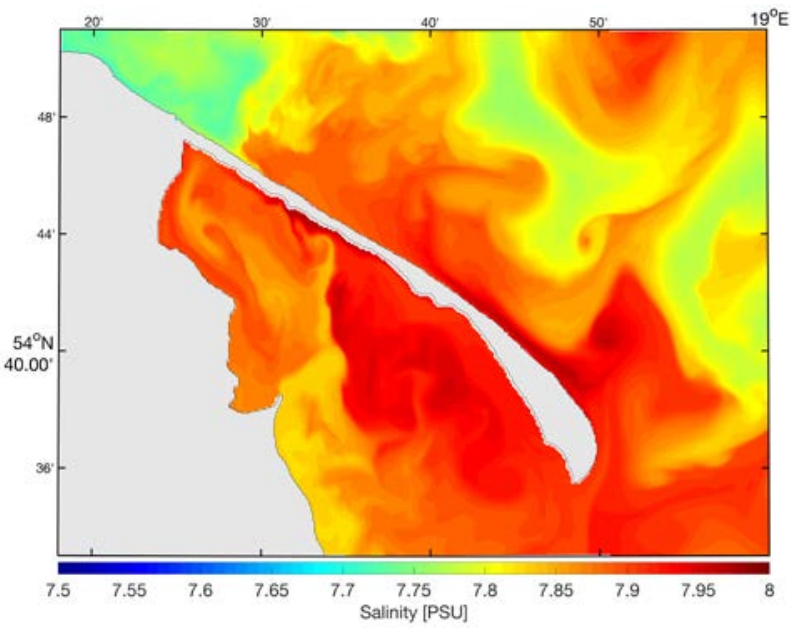

Fig. 10. Salinity distribution in the surface layer in Bay of Puck in November (3D EcoPuckBay).

The WaterPUCK service will enable to:

- calculate the sufficient amount of fertilizers that should be used (CalcGosPuck),

- investigate the nutrients and pesticides sources,

- model the fate and distribution of pollutants such as nutrients and pesticides in the surface water and groundwater,

- model loads of pollution to surface water and groundwater,

- model fluxes of nutrients via submarine groundwater discharge to the Baltic Sea coastal environment (Bay of Puck, Southern Baltic Sea),
- model the processes and mechanisms influencing the persistence of nutrients in the environment such as denitrification,

- predict the changes in land use and climate change influence on the ecosystem,

- calculate the sufficient amount of fertilizers that should be used (CalcGosPuck).

Due to the fact that inspectorates do not share collected data on the state and quality of the surface waters on a regular basis on a website and do not provide any other information service, WaterPUCK project goal is to fill this gap. WaterPUCK Integrated Information and Forecast Service will enable automatic calculation and transfer of data to the of the Puck Bay ecosystem model. Data would regard the size of nutrients and pesticides from models of surface and ground waters. WaterPUCK service will operate under dedicated management system of the individual modules in real time. This will allow generating 48-hour forecast for surface and ground water in the Puck commune mainly on the size of nutrients and pesticides delivered to the Puck Bay.

The WaterPUCK service will be available online for free, however the access to the CalcGosPuck calculator will be available by password given by the authority of the Puck District. Five years after the end of the project the authority of Puck District will make a fee for the WaterPUCK access.

\section{Discussion}

In Europe there are several eco-hydrological models in use originating from (or used by) different institutions or countries for example: SWIM (Soil and Water Integrated Model) from Potsdam Institute for Climate Impact Research; MIKE SHE by Danish DHI or MONERIS (Modelling Nutrient Emissions in River Systems) used for example to calculate the nutrient loads within the Danube river network. The most important is an interactive tool developed within the SWITCH-ON Project "eutrophication.eu" for analysing and planning cost effective measures to improve water quality. It works as a decision support system for water quality managers and stakeholders and can be used as a platform for sharing and communicating strategies for water quality improvement. It is based on HYPE hydrological model and covers whole Europe domain. This resolution implies very general (rough) mapping of the areas covered and ignores many of the small watercourses while focusing only on the biggest rivers within the domain.

Currently on Polish market a SWAT model (Soil and Water Assessment Tool) is commonly used. It will be used in the WaterPuck Service. It is a model invented in Texas, USA in the early 90 . It is a combination of earlier existing tools working in a river basin scale and was developed to quantify the impact of land management practices.

Groundwater modelling will be based on MODFLOW, which is the most widely used code for simulating groundwater flow and has been validated in 
hundreds of applications in many countries, including Poland. PHT3D is one of the most versatile packages for simulating the transport of dissolved substances undergoing chemical reactions.

When it comes to processes that occur in marine environment there are several scientific institutions in Europe that are engaged in modelling hydrodynamic and biochemical parameters of the Baltic Sea. In Sweden, the leader of numerical modelling is SMHI (Swedish Meteorological and Hydrological Institute), whose scientific work is based on the use of high-resolution ocean circulation model HIROMB (High Resolution Operational Model for the Baltic Sea), RCO (Rossby Centre Ocean Model), NEMO (Nucleus for European Modelling of the Ocean) and biogeochemical model SCOBI (Swedish Coastal and Ocean BIogeochemical model). Denmark uses the DMI/ERGOM and HIRLAM (High Resolution Limited Area Model) models. Common model also is ecosystem model of the Baltic Sea BALTSEM, the fruit of the international team of scientists work. None of the above models, however, has a comprehensive operating mode at the same time forecasting the risks associated with the change of hydrodynamic and biochemical parameters.

At the end of 2012, the operational ecohydrodynamic model 3D CEMBS (www.cembs.pl) has been initiated in the Institute of Oceanology of the Polish Academy of Sciences (IOPAS). It enables efficient and systematic monitoring of the Baltic Sea [7-8]. It is a z-level coordinates, general circulation ocean model that solves the 3-dimensional primitive equations for stratified fluid using the hydrostatic and Boussinesq approximations. $3 \mathrm{D}$ CEMBS is configured at approximately $2.3 \mathrm{~km}$ horizontal resolution $\left(1 / 48^{\circ}\right)$. Vertically model grid has 21 irregular layers. When water temperature within the grid cell drops below freezing point (salinity dependency equation) POP calls for CICE, which is responsible for numerical calculations of processes, related with sea ice variables. Atmospheric forcing data used in this simulation run origins from Unified Weather Prediction Model (UM) run at the Interdisciplinary Centre for Mathematical and Computational Modelling, University of Warsaw, Poland (www.meteo.pl). The hydrodynamic and biogeochemic variables are presented on the website in real time for a 48 -hour forecast. For our purposes, the Coupled Ecosystem Model of the Baltic Sea (CEMBS from IOPAS) is adapted to the Bay of Puck - we call it the Ecosystem Model of the Bay of Puck (3D EcoPuckBay).

The models included in the WaterPUCK Service have been adapted and work properly; those are physical models.

The key features that distinguish WaterPUCK Service among others are, according to its developers: complementarity, the use of available data, computational efficiency and predicting long-term effects.

\section{Conclusion}

The social and economic perspective of WaterPUCK aims to increase the environmental quality of the Puck Bay ecosystems under different scenarios of economic development. The growing pressure of agriculture, industry and tourism on the environment increases costs of maintaining biodiversity of the Baltic Sea and mitigation of eutrophic processes. What is more, the tourist attractiveness of the Baltic Sea decreases and the amount and variety of species of fish caught, give additional cost to coastal regions and municipalities. Therefore proposed solution and improvement is desired by both national and international communities.

The implementation of WaterPUCK and its possible transfer outside the pilot region, will require segmentation of the end-users and assessment of their readiness to use and further expand the functionality of the proposed system. Therefore, as a social demand assessment, several interactive workshops with different WaterPUCK related stakeholders will be organised to promote the project product.

This work was supported by the National Centre for Research and Development within the BIOSTRATEG III program No. BIOSTRATEG3/343927/3/NCBR/2017.

\section{References}

1. S.L. Neitsch, J.G. Arnold, J.R. Kiniry, J.R. Williams, K.W. King, BRC Report 02-05, TR-191. Coll. Stat. Tex.: Water Resour Manage (2002)

2. S.L. Neitsch, J.G. Arnold, J.R. Kiniry, J.R. Williams, Temple, Tex.: USDA-ARS Grassland. Soil Water Res. Lab (2005)

3. J. Brzozowski, Z. Miatkowski, D. Śliwiński, K. Sm arzyńska, M. Śmietanka, J. Water Land Dev. 15, 9 (2011)

4. S.D. Taylor, Y. He, K.M. Hiscock, J. Environ. Manag. 80, 17 (2016)

5. P. Zima, Pol. Marit. Res. 24, S1(93) (2017)

6. B. Jaworska-Szulc, Hydrogeol. J.17, 21 (2009)

7. L. Dzierzbicka-Glowacka, J. Jakacki, M. Janecki, A. Nowicki, Oceanologia 55, 22 (2013)

8. L. Dzierzbicka-Glowacka, M. Janecki, A. Nowicki, J. Jakacki, Oceanologia 55, 25 (2013)

9. B. Ulén, S. Pietrzak, K. S. Konderski, Selfevaluation of farms for improved nutrient management and minimized environmental impact. (ITLS, Falenty, Poland, 2013) 
10. M. Śmietanka, J. Water Land Develop. 21 (2014)

11. M.G. McDonald, A.W. Harbaugh, Techniques of Water-Resources Investigations (Geological Survey, Reston, VA, 1988)

12. M.P. Anderson, W. Woessner, Applied groundwater modeling: simulation of flow and advective transport. (Academic Press, London,1992) 